\title{
Maternal grief: analysis and therapeutic recommendations
}

\section{Janice Bell Meisenhelder}

School of Nursing, Emmanuel College, 400 The Fenway, Boston, Massachusetts, USA

\section{Correspondence to}

Dr Janice Bell Meisenhelder, Nursing, Wellesley, MA 02482, USA;

meisenhelderj@emmanuel.edu

Received 29 August 2020

Accepted 5 November 2020

Published Online First

25 November 2020

\section{Check for updates}

(c) Author(s) (or their employer(s)) 2021. No commercial re-use. See rights and permissions. Published by BMJ.

To cite: Meisenhelder JB. BMJ Supportive \& Palliative Care 2021;11:101-106.

\begin{abstract}
The following self-analysis contains key experiences of maternal grief over the course of the first 2 years following the death of a child, with specific examples and observations from bereaved mothers shared with the author. The references provide supporting evidence for commonality of the lived experience and observations. Therapeutic responses for clinicians give concrete direction for providing effective comfort. Self-care suggestions for mothers provide specific guidance for the readers. A 14year retrospective epilogue puts the charged emotional description into a context of healing.
\end{abstract}

All catastrophic loss has universal elements. This vivid description the bereavement experience provides clinicians with the insight needed for true empathic responses. This article is based on personal experiences of the author recorded at 2 years post the death of the child. The commonality of these descriptions are confirmed by the author's observations from years of peer counselling as well as recent research reports.

This self-study describes the experience of maternal loss of a 19-year-old daughter with cancer. The age of the child is significant for two reasons: (1) years of investment in caring and attaching to the child and (2) the maternal age eliminates having further children. Although initial years of maternal grief may be similar or parallel regardless of the child's age, the subsequent birth of another baby brings hope and images of a future, which were lost with the death of a child. Young couples that lose infants are forever changed by the loss but have a chance to recapture a future with additional children. Older couples that lose older children cannot create the same future in the same way. They must redefine a new future in a less satisfying way. Multiple studies document that increased material age at time of loss is associated with increased or prolonged grief with older mothers. ${ }^{1-5}$ Death of an adult child renders the same maternal grief, but more often remains invisible to those around her.

\section{SHOCK AND PAIN}

Like post-traumatic stress, the loss of a child is inconceivable. One is stunned, immobilised, catatonic with shock. The death of a life one has given with one's own body, brought into the world with one's own labour, renders the mother incapacitated. For months, the mother struggles to comprehend the unthinkable. This shock occurs regardless of whether the death was anticipated, for, until it happens, a mother cannot conceive of the death of a child emotionally. ${ }^{6}$ Such a thought is too unacceptable, even if she can rationally verbalise that inevitable outcome of a determined negative prognosis. Emotionally, death of one's own 'baby' remains unimaginable, even immediately after the event.

Simultaneously, the mother is plunged into indescribable pain. Like surviving a train wreck, but with every bone crushed and every organ bleeding, the pain is all consuming and inescapable, with an intensity that defies description. ${ }^{78}$ The shock fails to dull the intensity of the pain. Women commonly feel such acute pain that they are compelled to verbalise it loudly. The primal scream and the wailing sob demand expression. Mothers commonly react to the intensity of the pain with a death wish. The thought of living many years without her child is unbearable. The presence of a surviving child is the most powerful maternal incentive to go on living. Both the suicidal ideology and the desire to care for remaining children are documented in the current research on maternal bereavement. ${ }^{9-12}$

In this state of loss, the mother's ability to function is greatly reduced as symptoms of grief consume all areas of her life: cognitive dysfunction, physical symptoms, 


\section{Box 1 Goals of therapeutic}

1. Promote self-acceptance and self-forgiveness.

2. Educate on self-care strategies and healing practices.

3. Offer hope for healing and wholeness.

4. Refer to appropriate resources.

as well as the constant emotional turmoil. ${ }^{13}$ Although physical symptoms of grief such as insomnia, nausea, fatigue are common in many losses, in maternal grief such symptoms are more frequent, intense and long

Box 2 Therapeutic/helpful responses to the bereaved mother

1. Accept and normalise the mother's experience: ${ }^{832}$

- Provide a non-judgmental, accepting presence of listening.

- Affirm that feelings of guilt, envy, anger, loneliness and anxiety are commonly experienced by mothers who have lost children.

- Reassure the searing pain is expected, most mothers experience unspeakable suffering with the loss of a child.

- Reassure the intense yearning will soften over time, but may take months to years.

- Affirm the mother's perspective that her life is changed forever and will never be same.

- Encourage the mother to listen to her instincts on how best to heal.

2. Help set realistic self-expectations of healing and functioning.

- Mothers usually need time away from employment or other outside demands, at least for a few months, but often longer.

- Time and energy is needed just to comprehend the loss.

3. Provide continual, specific positive reinforcement and affirmation. ${ }^{37}$

- Positive feedback is the most powerful, yet underused form of help for people in grief.

- Point out every small positive aspect to this mother, from matching shoes to her ability to concentrate in a conversation.

- Her seeking support shows strength, and deserves affirmation.

4. Education on self-care strategies: physical, emotional, social, and spiritual.

- Encourage continued relationship with the deceased child, which is associated with lower anxiety and depression. ${ }^{29173138}$

5. Offer hope for the future

- Continually reassure the mother that her heartache will less over decades, even if it never resolves. Room for peace, love and joy will grow with time.

6. Education on resources, especially bereaved parent groups.

- The compassionate friends; Bereaved Parents of America and other similar groups. lasting, such as several years, decreasing slowing in intensity over time. ${ }^{1415}$ Loss of a child has been associated with higher morbidity and mortality. ${ }^{4516}$

Cognitively, all grief disrupts thought processes by the constant obsession of that which was lost. Bereaved mothers feel an insatiable, penetrating visceral hunger for the child that demands some satisfaction with some kind of sensual remainders: hearing the voice, seeing the photo, touching the objects, smelling the child's scent. $^{2917}$

Since the destruction of grief is so penetrating, the energy needed to heal is immense, and the time needed to heal lasts years. Thus, this state of lower adaptation lingers for a long time. Multiple studies document higher anxiety and post-traumatic stress following the loss of a child, which may last for years. ${ }^{510} 18$

\section{ACCOMPANYING EMOTIONS}

\section{Anger}

All human pain triggers an angry reaction. In grief, the anger may be aimed at God, the One who is suppose to prevent and protect such devastation, or at those who appeared to have caused the loss, as in an auto accident. ${ }^{1920}$ The extensive degree of pain results in huge amounts of anger that get diffusely expressed: from road rage to family bickering. A manifestation of grief, anger is a more culturally acceptable emotion than grief and easier to express. Anger is second degree grief, the outer layer of protection to attempt to smother the intense, overwhelming, and intolerable sense of loss. Under the anger lies the pain. Once the pain is expressed, the anger may well dissipate for some period. As the grief heals in a healthy way over the years, the anger dissolves, no longer needed.

\section{Envy}

'Why do others still have their children, while I am left with overwhelming emptiness and destructive grief?' Envy is an inevitable response to the fact that most other mothers never experience the deep pain of losing a child, although rarely openly verbalised. A mother in grief cannot help but wish to be one of the luckier mothers with all healthy, living children. Any reminder of those other happy, intact families may trigger more feelings of loss.

'Why do my friends expect me to be happy for them with these events, and invite me to celebrate with them, when any attempt to celebrate anything is a violation and insult to every emotion in my being?' While the sight of whole families painfully reminds the mother of her loss, the social pressure that join in their normal milestone celebrations betrays their complete misunderstanding of the level of her pain.

Mothers will often follow their instincts for selfprotection, and may need years to be able to resume total social expectations. One mother of a stillborn baby girl with no subsequent daughters refuses to attend girl baby showers, even 25 years after the loss. 


\section{Table 1 Self-care strategies for bereaved mothers}

Emotional
self-care $\begin{aligned} & \text { 1. Accept all your feelings: pain, anguish, yearning, anger, guilt, envy. Express it in any way possible as often as your instincts tell you to do } \\ & \text { so. } \\ & \text { 2. Listen to your instincts on how to cope. There is no 'right' way to navigate loss, for everyone has different needs. Avoid any self-judgement. } \\ & \text { Crying is a healthy way to let out the pain and make room for healing. } \\ & \text { 3. Find support in an accepting, listening presence. Seek multiple sources who can listen to you process this loss, friends, family, clergy or } \\ & \text { professional counselors. } \\ & \text { 4. Hold on to any objects that give you comfort for as long as you wish. If you need to pack the child's belongings away for your own comfort, } \\ & \text { avoid discarding them. Your need to connect with your child and ways to do so may change over the next few years. Research shows that } \\ & \text { parents have less distress when they stay connected to their child in whatever way is helpful. }{ }^{922} \text { 30 } \\ & \text { 5. Give yourself whatever sensory comfort you wish. Mothers often put worn clothes in plastic bags for preserving the child's scent, or } \\ & \text { preserve all voice recordings and remembrances. } \\ & \text { 6. Give yourself credit for every little action, including getting out of bed. Every movement is progress. } \\ & \text { 7. Ignore messages that you are to 'move on'. Mothers grieve and grow into new forms by keeping their children with them spiritually and } \\ & \text { emotionally, when the child is no longer physically present. } \\ & \text { Physical self-care } \\ & \text { 1. Physical self-care is a high priority, since even hygiene now takes more effort. } \\ & \text { 2. Try to make sleep, rest and heathy foods a priority } \\ & \text { 3. Many mothers experience physical symptoms of grief. Seek advice from your primary care professional for any concerns you have. } \\ & \text { 4. Cut back on all outside demands on your time, including employment. Your priority is your own healing and the needs of your immediate } \\ & \text { family. Self-care and family care is usually the most any grieving mother can do for the first few months. Wait until you truly feel ready } \\ & \text { before slowly re-entering activities. }\end{aligned}$

Another mother who lost a 20-year-old son refuses to attend weddings. Drawing such boundaries around oneself is a healthy protective mechanism. The difficult challenge is to insist on such boundaries being respected by those who cannot understand.

\section{Guilt: if only}

Maternal guilt has multiple layers. Regardless of how irrational, mothers usually feel responsible when any negative event has impacted their child. ${ }^{19-23}$ Mothers will examine repeated ways they might have anticipated the occurrence and intervened, even if such expectations are completely unrealistic to an outside observer.

In addition to guilt about the actual cause of death, mothers will also need to process other conflict or perceived failures in their own mothering. Thus, the 'if only I had...' response is repeated over and over, not only with the death-related event, but also potentially countless other events and memories.

Mothers need self-forgiveness, which may take a long time to come. The process of regret may need to be repeated until the mother can reach the inevitable, 'I did the best I could at the time'. Certainly, such fortification and reality reinforcement from trusted others serves to strengthen and hasten such healing. Forgiveness has a spiritual component and drawing on the mother's belief framework may also speed healing.

\section{Loneliness and isolation}

A catastrophic loss triggers intense empathy at the moment and shortly thereafter is forgotten by all except those traumatised by the loss. Social norms cue mothers to behave as if nothing happened. Often others feel helpless, inadequate, and afraid to raise the subject, thus reinforcing the tragedy as a taboo topic of conversation. Mothers seek out those who they may be able to share openly, but still mindful of the toll constant grief expressions may take on a friendship. Mothers may fear losing even close friends by the constant need to express their distress and talk of their child. Thus, mothers take on a balancing act, juggling their own needs with the preservation of the relationship.

One of the torturous components of maternal grief is the scarcity or absence of others who understand. ${ }^{24}$ The mother is best served by drawing close to others most effected by the loss. New bonds are possible with the others who loved her child, including the father and siblings. Families who can share their grief openly create most healthy atmosphere of positive coping and mutual support. ${ }^{25-27}$ The joint sense of loss allows for a more intense connection with those sharing that loss, bringing an element of healing into the bleak emptiness. For families, verbalising the feelings, sharing comforts and comforting each other must be blended with forgiveness and understanding as each person may be more irritable, self-absorbed and thoughtless in the midst of grief. Studies report that close family 
connections are associated with lower negative psychological outcomes of child loss. ${ }^{5}$ Certainly professional counselling for individuals and families may provide invaluable grief educational and emotional support.

\section{SELF-IMAGE: DESTROYED}

With the cognitive dysfunction comes the added distress at loss of one's capable self. Not only is one's usual love circle been ravaged, but one's own ability to cope or handle daily life is now disabled. The constant obsession of grief severely hampers the mother's ability to attend to other concerns, augmenting the sense of inadequacy and failure. It is impossible to feel good about oneself in the midst of constant pain.

The mother may be helped by keeping a record of what she was able to do that day, beginning with getting out of bed. Mothers need to change the scale of self-appraisal to be inline with what is realistic for someone recovering from a train wreck. Any small progress needs to be applauded and congratulated, from writing out thank you notes to making one's own meals. Mothers need to create a new self-image, which accepts the destruction of the loss and celebrates each tiny step towards healing, seeing survival as the ultimate goal.

The mother can also be encouraged to surround herself with affirming people and avoid those who are likely to undermine her efforts to heal. Social circles may change, and even family relationships may be altered as she encapsulates herself with the more positive environment during her highly vulnerable state. Focusing on surviving children, finding new purpose in life, and finding positive social support is linked to personal growth in parents in the first 18 months after the loss of a child. ${ }^{2}$

\section{EXISTENTIAL SUFFERING: SPIRITUAL DISTRESS Why me?}

'How can this possibly be' turns into 'why did this happen to my child!' The inconceivable must have a rhyme and reason. Random chance explanations offer no comfort, but rather mocks that life which was so sacred. The why-me question easily transfers into self-pity. Feeling the intense pain of loss can almost be impossible to separate from feeling sympathy for oneself. Awareness of one's own suffering highlights injustice of life, and with it, one's own misfortune.

Neither the existential questions nor the self-sympathy are useful processes. The self-focus of both seems to exacerbate the pain, rather than comfort or relieve it. Healing responses include doing something for someone else who is also suffering. In such giving lies the healing.

\section{Worry: life after death}

'Where is my child now?' This is a torturous worry for those without clear, definite answers and assurance. Mothers either believe or strive to believe in an afterlife or create a way for the child's memory to live on, or both.

The only answers to existential questions are spiritual. Mothers may turn to their own faith beliefs and may find the most help with spiritual counsellors and resources. Or they may reject long held beliefs and begin a search for new beliefs that they can embrace. Either way, the journey for meaning in suffering often accompanies such loss. ${ }^{28}$ Mothers may create their own meaning either instead of or in addition to their religious beliefs. Studies report lower symptoms of grief, lower depression, and greater personal growth in parents who used spiritual activities in their bereavement. ${ }^{929}$

The new meaning may involve new direction of work or life purpose for the mother. Examples of such a life change are parents who created a respite centre for disabled children, after loosing their own disabled child, or parents who opened a store focusing entirely on angels. Fund-raising events for significant causes or creating some form of positive social contribution signifies a healthy path to making meaning of the loss. Having a sense of life purpose has been associated with more positive well-being long term for bereaved parents. ${ }^{3031}$

\section{THERAPEUTIC RESPONSES TO A MOTHER'S GRIEF PAIN}

Support from both personal relationships and healthcare or spiritual professionals may provide critical education and reassurance in the first months or years. Boxes 1 and 2 provide the goals and strategies of therapeutic interaction, while table 1 provides the most critical, specific content that mothers need for self-care. Mothers need reassurance that this devastating reaction is typical and expected, as well as comfort that they will heal with time. Repeated reassurance that the pain will eventually decrease is essential in order to instil life-preserving hope. ${ }^{32} \mathrm{~A}$ free two-page handout for anyone experiencing loss is available at https:// www.mbmpublishers.com/surviving-the-unthinkable.

\section{EVALUATION 14 YEARS LATER}

The observations above describe processes in the first 2 years following the loss of a child. Bereaved parents commonly report that 'time does not heal', rather this loss is forever a heartache. ${ }^{11}$ Although, maternal longing for one's child remains lifelong, over decades, the intensity of the emotions and reactions describe above recedes dramatically ever so slowly over the years. ${ }^{33}{ }^{34}$ At the time of initial process of this content, the author was unable to imagine joy, although experiencing a great deal of peace. Slowly, the pain of grief subsides to be less of a major theme, allowing peace, love and joy to grow in prominence in the mother's life. Anger, envy, regret, posttraumatic stress, and loneliness resolve as grief diminishes and a new life is created over the years.

Parents commonly report 3-5 years to 'adjust' to the loss, to get accustomed to a 'new' normal. ${ }^{183536}$ However, healing continues well beyond five years. One mother at the 10-year postlost point reported that she could now enjoy Christmas more fully again. The sorrow never leaves, but grows to be more bittersweet, a mingling and cherishing of the positive memories along with the yearning to see and hold the child again. Post-traumatic 
growth expands during this decade, shown by the positive ways in which the mother honours the child's memory, such as fund raising for a cause or continuing traditions or rituals associated with the child. One woman baked a cake for her child's 40th birthday who had been deceased many years ago, which is a positive way to honour her child. Physical possessions and rituals that continue the bond with the child remain important and contribute positively to the mother's healing and peace throughout her life. ${ }^{917}$

\section{CONCLUSION}

Maternal bereavement leads to a cascade of negative and destructive responses in most mothers, requiring careful, deliberate and extensive care. The mother needs a supportive social network as well as professional help to navigate the intensity of the physical, cognitive, emotional and spiritual distress. An accepting, supportive and encouraging presence may help greatly to provide the reassurance, guidance and critical affirmation to help her not only survive, but even to grow through this catastrophic loss, a process that takes many years.

Contributors This is the work of JBM only.

Funding The authors have not declared a specific grant for this research from any funding agency in the public, commercial or not-for-profit sectors.

Competing interests None declared.

Patient consent for publication Not required.

Provenance and peer review Not commissioned; externally peer reviewed.

ORCID iD

Janice Bell Meisenhelder http://orcid.org/0000-0002-46448025

\section{REFERENCES}

1 Goldstein RD, Petty CR, Morris SE, et al. Pre-loss personal factors and prolonged grief disorder in bereaved mothers. Psychol Med 2019;49:2370-8.

2 O'Connor K, Barrera M. Changes in parental self-identity following the death of a child to cancer. Death Stud 2014;38:404-11.

3 Song J, Floyd FJ, Seltzer MM, et al. Long-term effects of child death on parents' health-related quality of life: a dyadic analysis. Fam Relat 2010;59:269-82.

4 Zheng Y, Lawson TR, Anderson Head B, Head B, et al. "Our only child has died"- - a study of bereaved older Chinese parents. Omega 2017;74:410-25.

5 Zhou N, Yu W, Huang H, et al. Latent profiles of physical and psychological outcomes of bereaved parents in China who lost their only child. Eur J Psychotraumatol 2018;9:1544026.

6 Kaye EC, Kiefer A, Blazin L, et al. Bereaved parents, hope, and realism. Pediatrics 2020;145:e20192771.

7 Chen L, Fu F, Sha W, et al. Mothers coping with bereavement in the 2008 China earthquake: a dual process model analysis. Omega 2019;80:69-86.

8 Denhup C. Bereavement care to minimize bereaved parents' suffering in their lifelong journey towards healing. Appl Nurs Res 2019;50:151205.

9 Tan PP, Ketola J. Bereaved mothers Navigating the impact of their loss. Illn Crises Loss 2013;21:141-55.

10 Shifa G, Ahmed A, Yalew W. The relationship between under-five child death and maternal mental distress in
Gamo Gofa zone, southern Ethiopia: a community based comparative cross-sectional study.. BMC Womens Health $2019 ; 18$.

11 Sugrue JL, McGilloway S, Keegan O. The experiences of mothers bereaved by suicide: an exploratory study. Death Stud 2014;38:118-24.

12 Thieleman K, Cacciatore J. "As if nothing happened": experiences of bereaved parents in Romania. Omega 2020;81:685-705.

13 Dias N, Brandon D, Haase JE, et al. Bereaved parents' health status during the first 6 months after their child's death. Am J Hosp Palliat Care 2018;35:829-39.

14 Yin Q, Shang Z, Zhou N, et al. An investigation of physical and mental health consequences among Chinese parents who lost their only child. BMC Psychiatry 2018;18:45.

15 Youngblut JM, Brooten D. Comparison of mothers and grandmothers physical and mental health and functioning within 6 months after child NICU/PICU death. Ital J Pediatr 2018;44:89.

16 Valdimarsdo U, Lu D, Lund S, et al. The mother's risk of premature death after child loss across two centuries. eLife.

17 Goldstein R, Petty C, Morris S, et al. Transitional objects of grief. Compr Psychiatry.

18 Wikman A, Mattsson E, von Essen L, et al. Prevalence and predictors of symptoms of anxiety and depression, and comorbid symptoms of distress in parents of childhood cancer survivors and bereaved parents five years after end of treatment or a child's death. Acta Oncol 2018;57:950-7.

19 Fu F, Chen L, Sha W, et al. Mothers' grief experiences of losing their only child in the 2008 Sichuan earthquake: a qualitative longitudinal study. Omega 2020;81:3-17.

20 Titlestad K, Mellingen S, Stroebe M, et al. Sounds of silence. The "special grief" of drug-death bereaved parents: a qualitative study. Addict Res Theory 2020;20.

21 Huh HJ, Kim KH, Lee H-K, et al. Attachment styles, grief responses, and the Moderating role of coping strategies in parents bereaved by the Sewol ferry accident. Eur J Psychotraumatol 2017;8:1424446.

22 Lichtenthal WG, Roberts KE, Catarozoli C, et al. Regret and unfinished business in parents bereaved by cancer: a mixed methods study. Palliat Med 2020;34:367-77.

23 Sim Chu-Won, Heuse S, Weigel D, et al. If only I could turn back time-Regret in bereaved parents. Pediatr Blood Cancer 2020;67.

24 Gerrish N, Bailey S. Maternal grief: a qualitative investigation of mothers' responses to the death of a child from cancer. Omega 2020;81:97-241.

25 Cao X, Yang C, Wang D. The impact on mental health of losing an only child and the influence of social support and resilience. Omega 2020;80:666-84.

26 Dyregrov A, Gjestad R, Dyregrov K. Parental relationships following the loss of a child. J Loss Trauma 2020;25:224-44.

27 Song J, Floyd FJ, Seltzer MM, et al. Long-term effects of child death on parents' health related quality of life: a Dyadic analysis. Fam Relat 2010;59:269-82.

28 Albuquerque S, Buyukcan-Tetik A, Stroebe MS, et al. Meaning and coping orientation of bereaved parents: individual and dyadic processes. PLoS One;12:e0178861.

29 Hawthorne DM, Youngblut JM, Brooten D. Parent spirituality, grief, and mental health at 1 and 3 months after their Infant's/Child's death in an intensive care unit. J Pediatr Nurs 2016;31:73-80.

30 Rogers CH, Floyd FJ, Seltzer MM, et al. Long-term effects of the death of a child on parents' adjustment in midlife. J Fam Psych 2008;22:203-11.

31 Waugh A, Kiemle G, Slade P. What aspects of post-traumatic growth are experienced by bereaved parents? A systematic review. Eur J Psychotraumatol 2018;9:1506230. 
32 Barlé N, Wortman CB, Latack JA. Traumatic bereavement: basic research and clinical implications. J Psychother Integr 2017;27:127-39.

33 Aho AL, Malmisuo J, Kaunonen M. The effects of peer support on post-traumatic stress reactions in bereaved parents. Scand J Caring Sci 2018;32:326-34.

34 Cacciatore J, Killian M, Harper M. Adverse outcomes in bereaved mothers: the importance of household income and education. SSM Popul Health 2016;2:117-22.

35 Lykke C, Ekholm O, Schmiegelow K, et al. Anxiety and depression in bereaved parents after losing a child due to lifelimiting diagnoses: a Danish nationwide questionnaire survey. $J$ Pain Symptom Manage 2019;58:596-604.
36 Pohlkamp L, Kreicbergs U, Sveen J. Bereaved mothers' and fathers' prolonged grief and psychological health 1 to 5 years after loss-A nationwide study. Psychooncology 2019;28:1530-6.

37 Rack JJ, Burleson BR, Bodie GD, et al. Bereaved adults' evaluations of grief management messages: effects of message person centeredness, recipient individual differences, and contextual factors. Death Stud 2008;32:399-427.

38 Field NP, Packman W, Ronen R, et al. Type of continuing bonds expression and its comforting versus distressing nature: implications for adjustment among bereaved mothers. Death Stud 2013;37:889-912. 